\author{
Jin Gu Kang \\ Moon Chan Kim \\ I Rok Shin \\ Woo Seok Jin
}

http://dx.doi.org/10.21278/brod72406

ISSN 0007-215X

eISSN 1845-5859

\title{
FEASIBILITY STUDY ON EFFECT OF STRUCTURAL FLEXIBILITY OF ASYMMETRIC PRE-SWIRL STATOR ON PROPULSION PERFORMANCE FOR KRISO CONTAINER SHIP (KCS)
}

UDC 629.544:629.5.015.4

Original scientific paper

\begin{abstract}
Summary
The use of energy-saving devices is the most effective method for decreasing $\mathrm{CO} 2$ emissions, which is an increasingly concerning environmental issue. The asymmetric preswirl stator has been developed as an energy-saving device and has been successfully applied to various types of vessels. In the present study, a flexible material was applied to an asymmetric pre-swirl stator to determine the variation in the flow around stator and its efficiency. A fluid-structure interaction (FSI) analysis system was developed using the Star$\mathrm{CCM}+$ (fluid) and the Abaqus (structure). The proposed analysis system was validated by comparing the experimental results using a flexible plate in a flowing fluid. The flexible stator was applied to a 3,600 TEU KRISO Container Ship to determine the improvement in its performance compared to the previous optimum value achieved with a rigid stator. Although this application was conducted on a model scale and the deformation was small, the results of the flexible stator indicated the possibility of not only increasing the efficiency but also decreasing the vortex risk around stator blade.
\end{abstract}

Key words: $\quad$ pre-swirl stator (PSS); fluid-structure interaction (FSI); flexible material; energy-saving device (ESD)

\section{Introduction}

Environmental regulations are becoming more significant; therefore, the International Maritime Organization (IMO) is reinforcing regulations in the ocean that it had initiated against CO2, NOx, and SOx (representative ship exhaust gases) based on the energy efficiency design index (EEDI) [1]. Accordingly, energy-saving devices (ESDs) have been developed to reduce the EEDI. ESD development is critical for reducing not only the energy consumption but also the $\mathrm{CO} 2$ emissions of ships. As depicted in Fig. 1, ESDs can be classified into the following three zones: pre-device (Zone I), main device (Zone II), and postdevice (Zone III) [2]. 


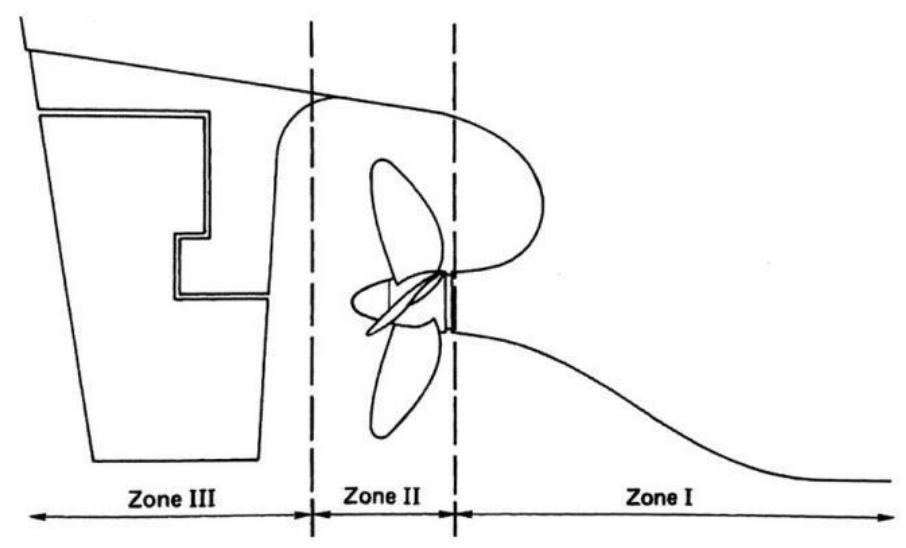

Fig. 1 Zone-wise classification of energy-saving devices

This study focuses on the asymmetric pre-swirl stator (pre-device) because it is currently regarded as the most effective device and has been frequently applied without any major problems. In Korea, major shipbuilding companies (DSME, Samsung Heavy Ind., etc.) have adopted asymmetric pre-swirl stators in various types of vessels.

A pre-swirl stator improves the propulsion efficiency by recovering the rotational energy that is generated during the propeller rotation via the stator blades placed in front of the propeller. In this study, we have developed a new asymmetric pre-swirl stator with three blades on the port side and one blade on the starboard side, as depicted in Fig. 2 [3]. Previously, the symmetric six blade stator was used for practical applications [4].

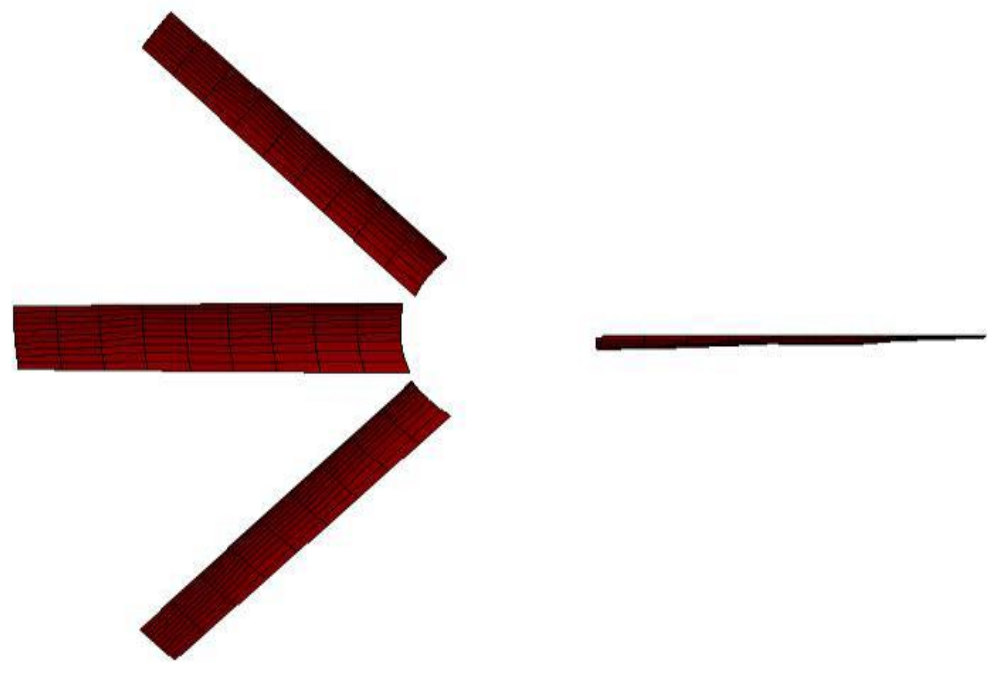

Fig. 2 Profile of an asymmetric pre-swirl stator (in the upstream direction)

The proposed asymmetric pre-swirl stator has fewer blades on the starboard side. This is because the rotational flow component is different on each side owing to the upward flow. The upward velocity is normally cancelled by the rotational velocity of the propeller on the starboard side, whereas that on the port side is doubled. The application of an asymmetric preswirl stator to a $300 \mathrm{~K}$ very large crude oil carrier helped increase the efficiency by more than $5 \%$ [3]. Several studies have been conducted on asymmetric stators. Typical attachment examples are depicted in Fig. $3[5,6]$. 


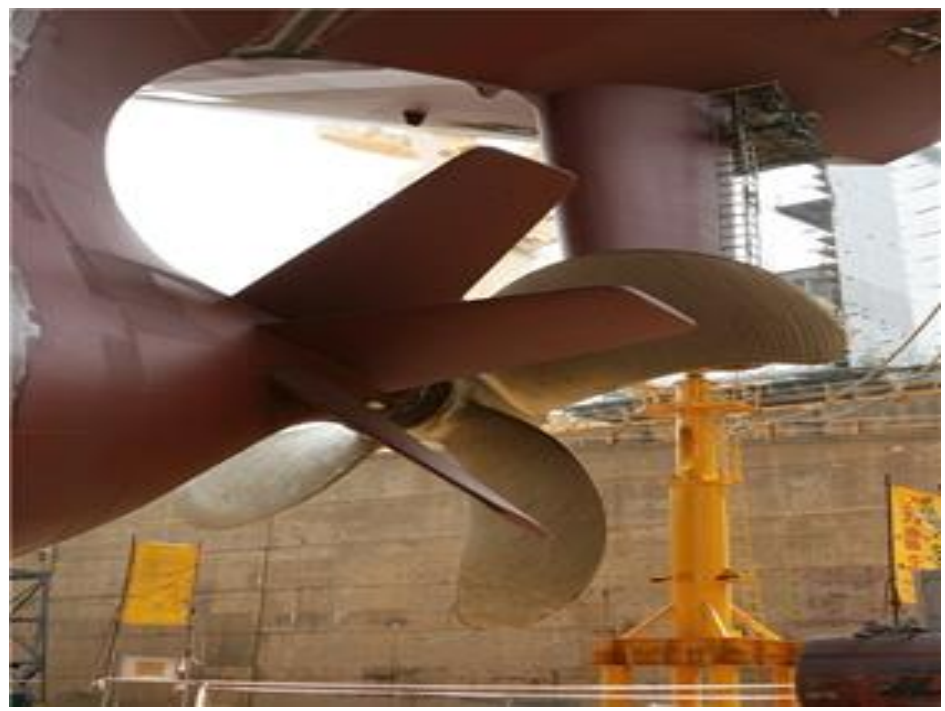

Fig. 3 Asymmetric pre-swirl stator installed by DSME in 2006

The stator has been frequently used in more than 200 vessels by the DSME. The strong stator tip vortex has been found to occasionally damage the propeller and rudder surfaces. The stator pitch angle is complex to design for it to adapt to the flow angle owing to the nonuniform wake field, especially while using a constant pitch angle type stator. Most stators are manufactured with a constant pitch angle, considering their cost effectiveness. Although the variable pitch angle type stator is used to adapt to non-uniform flow, the prediction of a fullscale effective wake in actual ships remains uncertain.

The application of flexible materials is one of the best solutions to resolve this problem by adjusting the section reference line to the inflow by twisting the tip trailing edge. Although the flexibility of the material is not significantly high, it may be effective owing to a thin tip. There are several advantages for using a flexible material in the ESD owing to its lightweight (less structural burden in the astern part), as well as the low unsteadiness, in addition to efficiency increase. Additionally, as even commercial ships often have multiple design point different from the initial design condition due to a change of circumstance, the flow into stator becomes different from initial design condition, that might cause an unexpected efficiency loss and also unfavourable of cavitation problem. In such cases the present flexible stator might works better than the rigid case by adjusting stator section with the oncoming flow. In particular, the difference in ship loading condition may vary the conditions of the oncoming flow or the ship speed mentioned above. It is thought that the application of the flexible stator can be achieved sufficient efficiency compared to the rigid stator even if the loading condition of the ship is different.

This type of application was initiated by the aerospace field with a composite material that was not significantly flexible at that time [7]. However, this application is being extended to naval architecture owing to the characteristics of the composite material, such as its light weight, impact resistance, and corrosion resistance. Flexible materials for propulsion systems in ships have been mostly applied to navy vessels for achieving better performance at the cavitation inception speed (CIS), as well as noise and vibration due to the cavity. However, studies regarding navy vessels with flexible materials are limited because of confidentiality issues. Although few studies were conducted on the submarine, the target vessel was not full scale $[8,9]$. Recently, this application was extended to commercial ships. The Japanese shipyard applied a flexible propeller to a commercial ship, as depicted in Fig. 4 [10]. 


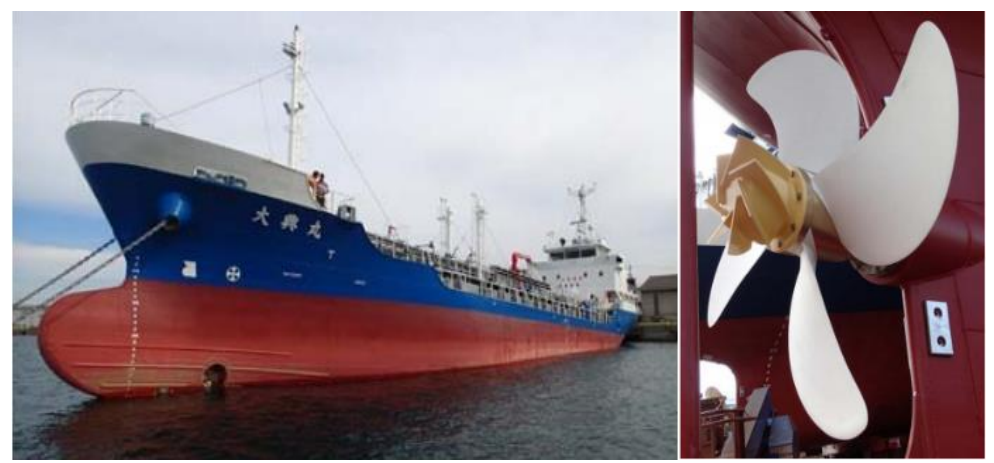

Fig. 4 499G/T Chemical tanker "TAIKO-Maru" with composite propeller

Park et al. 2013 [11] also verified the performance of a rudder with an FRP composite material for a full-scale fishing vessel. Performance including speed, fuel consumption, and maneuverability was investigated and determined to be better than that of a conventional rudder. Regarding the ESD for commercial ships, flexible materials have apparently not been applied thus far.

For analysing issues regarding fluid-structure interaction (FSI), the VLM-FEM coupling method was first developed by Lin et al. 1996 [12] and was used for cases that were flexible to a certain extend. However, because this method is based on a linear theory, it disregards the interaction between wing thickness and load; errors occur when the blade is thick, and the thick blade cannot be used in local flow analysis, such as the blade tip vortex. Therefore, a potential BEM-FEM analysis method was developed and widely used [13-15]. However, this method was also considered inaccurate while predicting the flow at the tip of the blade because the Kutta condition did not converge for a large skew angle or a long chord length at the tip of the blade. Recently, to increase the accuracy, especially for the fluid problem, the CFD, including the viscous effect, has become more popular when compared to the BEM potential method [16]. Considering FSI analysis, Maljaars and Kaminski [17] provided an overview of previous studies regarding the hydro-elastic analysis of flexible propellers, in which it was indicated that comparative studies based on various hydrodynamic analyses are limited. Regarding the partitioned and the monolithic coupling approaches for FSI calculations, the former provides more opportunities. Regarding the experimental studies, measuring the deformations of flexible propellers, even in a steady flow, has not been previously demonstrated. In addition, the scaling of flexural strength for a full-scale experimental prediction is difficult because the scaled flexural strength is significantly low for a model. Although a precise full-scale prediction remains complex because of the aforementioned limitation, this study considers a model scale that may be a step toward the final application.

In this study, for a more accurate computation, a CFD-FEM two-way coupling method was adopted by using the commercial code Star-CCM+ (hydrodynamics analysis) and Abaqus (structural analysis). A flexible plate with a low density was used to validate the developed FSI analysis system by comparing it with the experimental data. The validated analysis code was applied for analysing the flexible asymmetric pre-swirl stator and propeller system for the KRISO container ship (KCS). As previously indicated, the rigid (non-flexible) stator for KCS was optimized through long term studies [6]. Based on the final results, the thickness of the stator was reduced to confirm the flexible effect. This study might provide the possibility of the application of flexible materials to the ESD although the application is still in the model scale, and the deformation is small. The results of the KCS stator in this study can be optimized by varying the flexibility, which is a future scope of this study. Moreover, a model test for realizing a flexible ESD and determination of the optimum shape of the tip configuration are also expected to be conducted in the near future. 


\section{CFD-FEM Based FSI Validation}

To determine the effectiveness of applying a flexible asymmetric pre-swirl stator, the FSI analysis was conducted via the iteration between a fluid analysis with the Star-CCM+ and a structure analysis with the Abaqus until convergence. Two-way interaction between CFD and FEA is conducted by implicit coupling algorithm. Two-way coupling can be further classified into explicit and implicit couplings. When the mutual dependency on time is high between the fluid and structure solutions and a small change in one solver will have an immediate effect on the other, an implicit coupling scheme is preferred as Fig. 5.

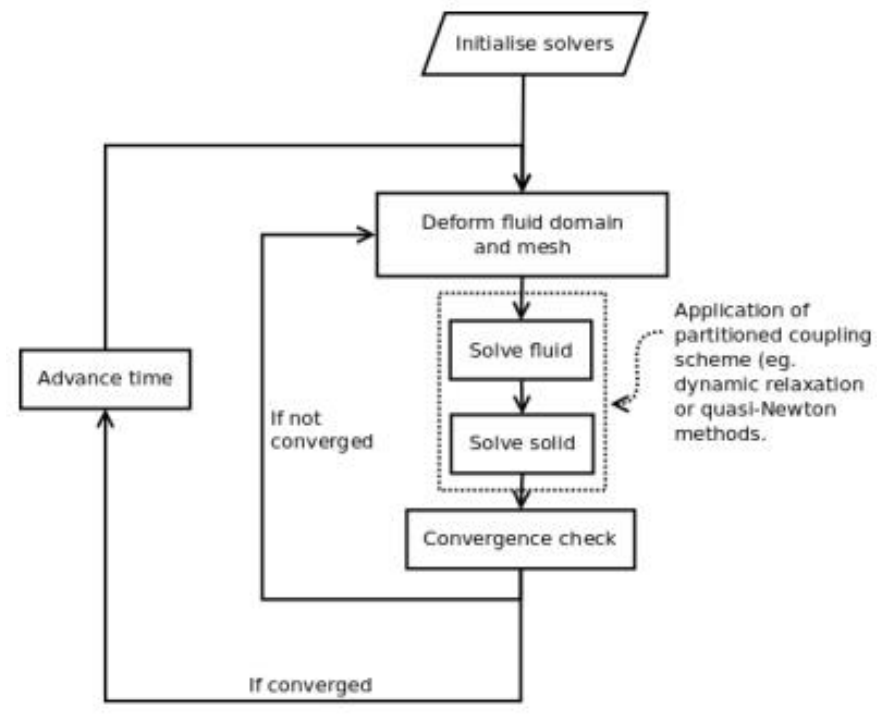

Fig. 5 Flowcharts illustrating of implicit (strong) coupling [18]

A relatively simple problem was selected to validate the proposed FSI analysis system. Owing to the existing experimental data regarding the validation of the bending deformation of an elastic plate, it was adopted with a fixed bottom and a normal cross flow condition, as depicted in Fig.5. The geometry of the plate used in the analysis is also depicted in Fig. $6(\mathrm{~L}=$ $0.05 \mathrm{~m}, \mathrm{~h}=0.002 \mathrm{~m}, \mathrm{~b}=0.01 \mathrm{~m})$. The plate with the material properties of silicone foam $(\rho=$ $694.95 \mathrm{~kg} / \mathrm{m} 3, \mathrm{E}=500 \mathrm{kPa}, v=0.4)$ was vertically placed in a normal uniform flow $\left(\mathrm{U}_{0}=\right.$ $0.16 \mathrm{~m} / \mathrm{s}, \rho=1025 \mathrm{~kg} / \mathrm{m} 3, \mathrm{Re}=1600)$. The implicit coupling scheme was used with multiple data exchange points during onetime step. In the case of the implicit scheme, although the calculation time was longer than that of the explicit scheme, it was necessary to perform accurate calculations to reflect the complex flow near the propeller. The detailed analysis conditions are presented in Table 1.

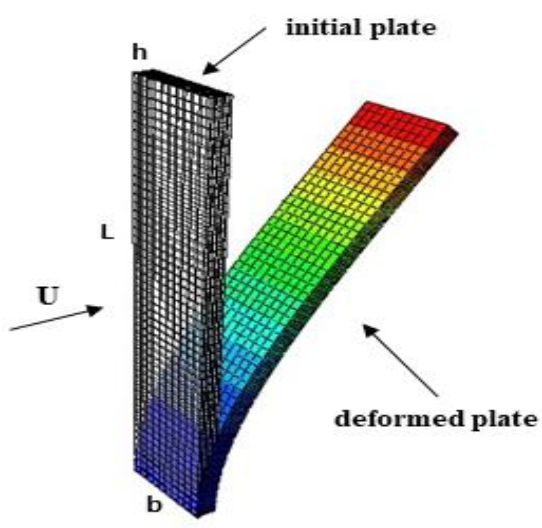

Fig. 6 Profile of the bending plate normally flowing flow 
Table 1 Computational conditions of the FSI analysis for the plate case

\begin{tabular}{|l|l|}
\hline Program & $\begin{array}{l}\text { Star-CCM+ (Ver. 11.02) } \\
\text { Abaqus (Ver. 6.14) }\end{array}$ \\
\hline Governing Equation & Incompressible RANS Equation \\
\hline Turbulence Model & Realizable $\mathrm{k}-\varepsilon$ model \\
\hline Coupling Scheme & Implicit \\
\hline Time Step & $0.0005 \mathrm{~s}$ \\
\hline Physical Time & $5 \mathrm{~s}$ \\
\hline Grid No. & Approximately 2,000,000 \\
\hline
\end{tabular}

The boundary conditions and grid system are illustrated in Fig. 7. Finer grids were generated near the plate to capture the deformed motion more accurately. A numerical analysis was conducted in three grid systems to determine the grid dependency. The number of fine, medium, and coarse grids were approximately 2 million, 1 million, and 500,000, respectively. In the coordinate system, the direction of uniform flow $U$ is positive $x$, and the direction of spanwise of the plate is $\mathrm{z}$.
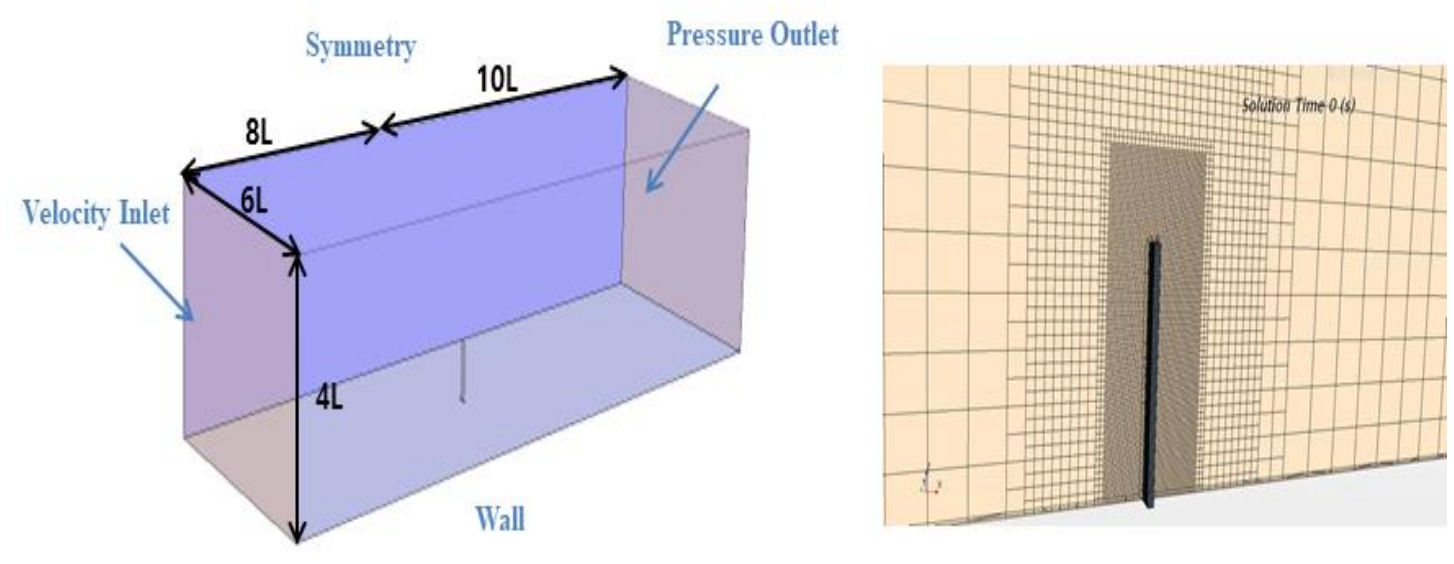

Fig. 7 Boundary conditions and grid system for the bending plate problem

The displacements of deflection in the $\mathrm{X}$ and $\mathrm{Z}$ directions (i.e., Dx and Dz) with the free end are listed in Table 2, which are compared with the experimental results [19]. The coordinates are defined in the $\mathrm{h}$ direction and $\mathrm{z}$ in the $\mathrm{L}$ direction, as depicted in Fig. 6 . The dimensionless deformations in the $\mathrm{X}$ and $\mathrm{Z}$ directions by the breath $\mathrm{b}$ are compared in Table 2 , including the experimental data according to the density of the grid for validating grid dependency. Although there is a difference in Dz, the correlation is apparently sufficient; the converged results from the medium grid system are shown. Because the material used in this study has a low density (flexible), compared to the material of an asymmetric stator (later), the validated system could sufficiently be applied to the FSI computation of an asymmetric stator in the KCS. 
Table 2 Comparison of computed deformation with the experimental result and grid dependency

\begin{tabular}{|r|r|r|r|r|r|r|r|}
\hline & EFD [20] & Coarse & $\begin{array}{c}\text { Difference } \\
(\%)\end{array}$ & Medium & \multicolumn{1}{|c|}{$\begin{array}{c}\text { Difference } \\
(\%)\end{array}$} & Fine & $\begin{array}{c}\text { Difference } \\
(\%)\end{array}$ \\
\hline Dx/b & 2.14 & 2.19 & 2.34 & 2.18 & 1.87 & 2.18 & 1.87 \\
\hline $\mathrm{Dz} / \mathrm{b}$ & 0.59 & 0.63 & 6.78 & 0.62 & 5.08 & 0.62 & 5.08 \\
\hline
\end{tabular}

\section{Target Ship and Propeller}

In this study, we selected a 3,600 TEU KCS as the target ship and the KP505 as the propeller model. The model scale ratio and design speed are 39.5 and $1.964 \mathrm{~m} / \mathrm{s}$, respectively, and the dimensions of the target ship and propeller are summarized in Tables 3 and 4, respectively. Their configurations are depicted in Fig. 8.

Table 3 Principal dimensions of the target ship (KCS)

\begin{tabular}{|c|c|c|}
\hline & Real Scale & Model Scale \\
\hline Length PP $(\mathrm{m})$ & 230.00 & 5.82 \\
\hline Length WL $(\mathrm{m})$ & 232.50 & 5.89 \\
\hline Breadth $(\mathrm{m})$ & 32.20 & 0.82 \\
\hline Depth $(\mathrm{m})$ & 19.00 & 0.48 \\
\hline Design Draught $(\mathrm{m})$ & 10.80 & 0.27 \\
\hline CB & 0.651 & 3.82 \\
\hline Design Speed (knots) & 24.0 & \\
\hline Scale Ratio & & 39.5 \\
\hline
\end{tabular}

Table 4 Principal dimensions of the target propeller (KP505)

\begin{tabular}{|c|c|c|}
\hline & Real Scale & Model Scale \\
\hline Number of Blades & \multicolumn{2}{|c|}{5} \\
\hline Diameter (m) & 7.9 & 0.2 \\
\hline P/D at 0.7R & 0.997 \\
\hline C/D at 0.7R & 0.359 \\
\hline t/D at 0.7R & 0.015 \\
\hline Expanded Area Ratio & 0.795 \\
\hline Section Type & NACA \\
\hline Scale Ratio & 39.5 \\
\hline
\end{tabular}




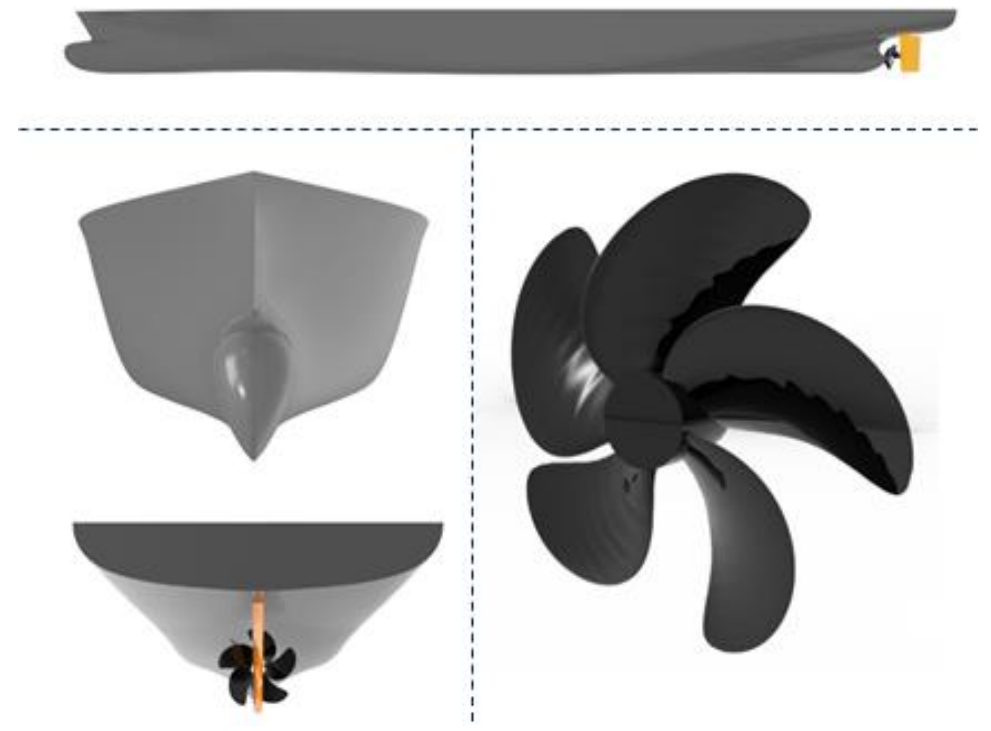

Fig. 8 Three-dimensional configurations of 3,600TEU KRISO container ship and KP505 propeller

\section{Validation of Optimally Designed PSS for KCS}

The asymmetric pre-swirl stator proposed by Shin et al. [6] was used for validating this study. The specifications of the optimally designed asymmetric pre-swirl stator and the pitch angle of each blade are listed in Tables 5-6. In Table 5, $\mathrm{r}$ is the radius, $\mathrm{c}$ is the chord length of the stator section, $\mathrm{D}$ is the diameter of the PSS, and $\mathrm{f}_{0}$ is the camber. In Table 6 , the pitch angle of each blade $(\Phi)$ is the same for each radius $(r)$, and the pitch of the stator $(P)$ is expressed as an angle, as expressed in equation (1). The configuration of the asymmetric preswirl stator is depicted in Fig. 9. The numerical validation was per-formed by comparing the self-propulsion performance with that of the previous results [6]. Further, the thickness of the blade and grid system are slightly different: finer than before for a more complicated FSI analysis. The thickness was taken $20 \%$ smaller than the previous stator to find out the effect of blades flexibility.

$$
90-\Phi=\tan ^{-1} \frac{P}{2 \pi r}
$$

Table 5 Geometry of the asymmetric pre-swirl stator for KCS

\begin{tabular}{|l|l|l|l|}
\hline $\mathrm{r} / \mathrm{R}$ & $\mathrm{c} / \mathrm{D}$ & $\mathrm{f}_{0} / \mathrm{c}$ & $\mathrm{t} / \mathrm{D}$ \\
\hline 0.20 & 0.177 & 0.085 & 0.037 \\
\hline 0.25 & 0.174 & 0.082 & 0.035 \\
\hline 0.30 & 0.171 & 0.078 & 0.033 \\
\hline 0.40 & 0.165 & 0.071 & 0.030 \\
\hline 0.50 & 0.159 & 0.063 & 0.026 \\
\hline 0.60 & 0.153 & 0.054 & 0.023 \\
\hline 0.70 & 0.147 & 0.045 & 0.019 \\
\hline 0.80 & 0.142 & 0.035 & 0.016 \\
\hline 0.90 & 0.136 & 0.025 & 0.012 \\
\hline 0.95 & 0.133 & 0.019 & 0.011 \\
\hline 1.00 & 0.130 & 0.013 & 0.009 \\
\hline
\end{tabular}


Table 6 Pitch angle of each blade

\begin{tabular}{|c|c|c|}
\hline Stator & Position & Designed Pitch Angle \\
\hline First blade & $45^{\circ}$ & $5.0^{\circ}$ \\
\hline Second blade & $90^{\circ}$ & $10.0^{\circ}$ \\
\hline Third blade & $135^{\circ}$ & $2.0^{\circ}$ \\
\hline Fourth blade (Starboard) & $270^{\circ}$ & $1.5^{\circ}$ \\
\hline
\end{tabular}

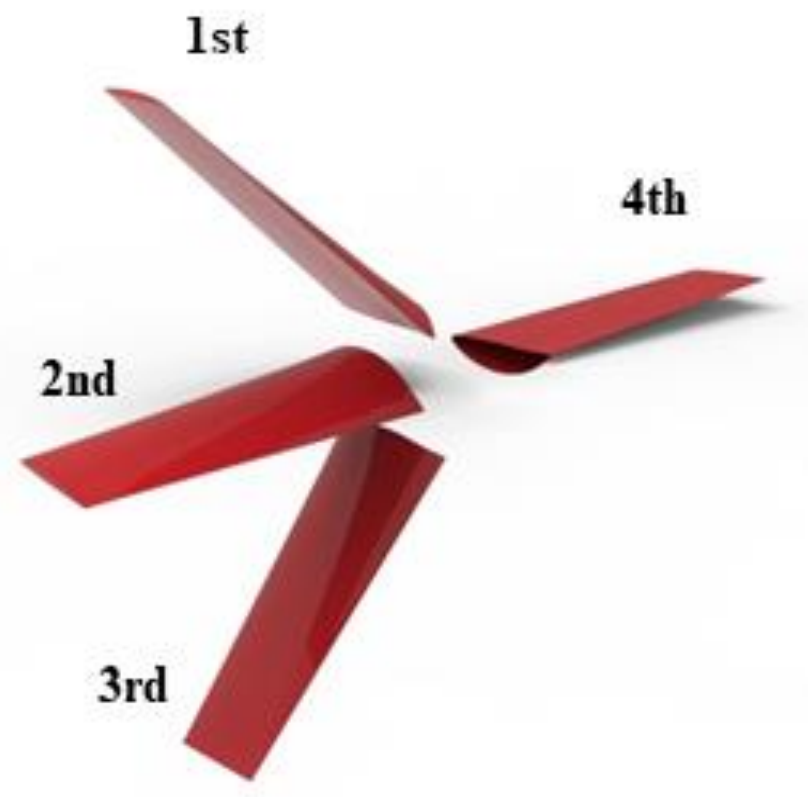

Fig. 9 Configuration of the asymmetric pre-swirl stator (each blade in the upstream direction)

The commercial CFD program Star-CCM+ (Ver. 11.02) was used for the validation. A self-propulsion analysis of the KCS with an asymmetric pre-swirl stator (optimally designed in a previous study) was conducted and validated by comparing the delivered power of the model ship at the self-propulsion point with the results of a previous study.

The continuity equations (governing equations of incompressible turbulent flow) as well as the Reynolds averaged Navier-Stokes equations were used, which can be expressed as follows:

$$
\begin{aligned}
& \frac{\partial u_{i}}{\partial x_{i}}=0 \\
& \frac{\partial\left(\rho u_{i}\right)}{\partial t}+\frac{\partial\left(\rho u_{i} u_{j}\right)}{\partial x_{i}}=-\frac{\partial p}{\partial x_{i}}+\frac{\partial}{\partial x_{i}}\left(-\rho \overline{\dot{u}_{i} \dot{u}_{j}}\right)+\frac{\partial}{\partial x_{i}}\left[\mu\left(\frac{\partial u_{i}}{\partial x_{j}}+\frac{\partial u_{j}}{\partial x_{i}}\right)\right]
\end{aligned}
$$

Where $u_{i}, p, t, \rho, \mu$, and $-\rho \overline{\dot{u}_{\imath} \dot{u}_{\jmath}}$ correspond to the speed, pressure, time, density, dynamic viscosity coefficient, and Reynolds stress tensor, respectively.

The governing equations were solved using the finite volume method. The velocitypressure coupling was also used by the semi-implicit method for pressure linked equations those were consistent with the SIMPLE algorithm, and the turbulent model was the realizable К- $\varepsilon$ model. The computational conditions are presented in Table 7. Additionally, CFD analysis took approximately 2 days to calculate using 140 cores of CPU (Intel_Xeon_E52650_v2_@_2.60GHz). 
Table 7 Computational conditions for CFD

\begin{tabular}{|l|l|}
\hline Program & Star-CCM+ (Ver. 11.02) \\
\hline Governing Equation & Incompressible RANS Equation \\
\hline Discretization & Cell centered FVM \\
\hline Turbulence Model & Realizable $\mathrm{k}-\varepsilon$ model \\
\hline Rotation Method & Sliding Mesh \\
\hline Time Step & 0.002s \\
\hline Physical Time & 20s \\
\hline Grid No. & $\begin{array}{l}\text { Approximately 3,500,000 } \\
\text { (Fluid region: 2.6M, Rotating region: }\end{array}$ \\
\hline
\end{tabular}

The boundary conditions and grid system were set as depicted in Fig. 10, where L represents the length of the ship. The domain was composed of a sufficient distance to avoid affecting the flow analysis. The boundary conditions were set to the top, inlet, bottom for velocity inlet, side for symmetry, and outlet for pressure outlet. In the grid system, the domain region including the hull was composed of trimmer grids; the number of cells was approximately 2.5 million, the rotation region including the propeller was composed of polyhedral grids, and the number of cells was approximately 1 million. The free surface flow was analysed using the volume of fluid (VOF) method, and the sliding mesh method was used to simulate the rotational flow of the propeller wake more accurately.

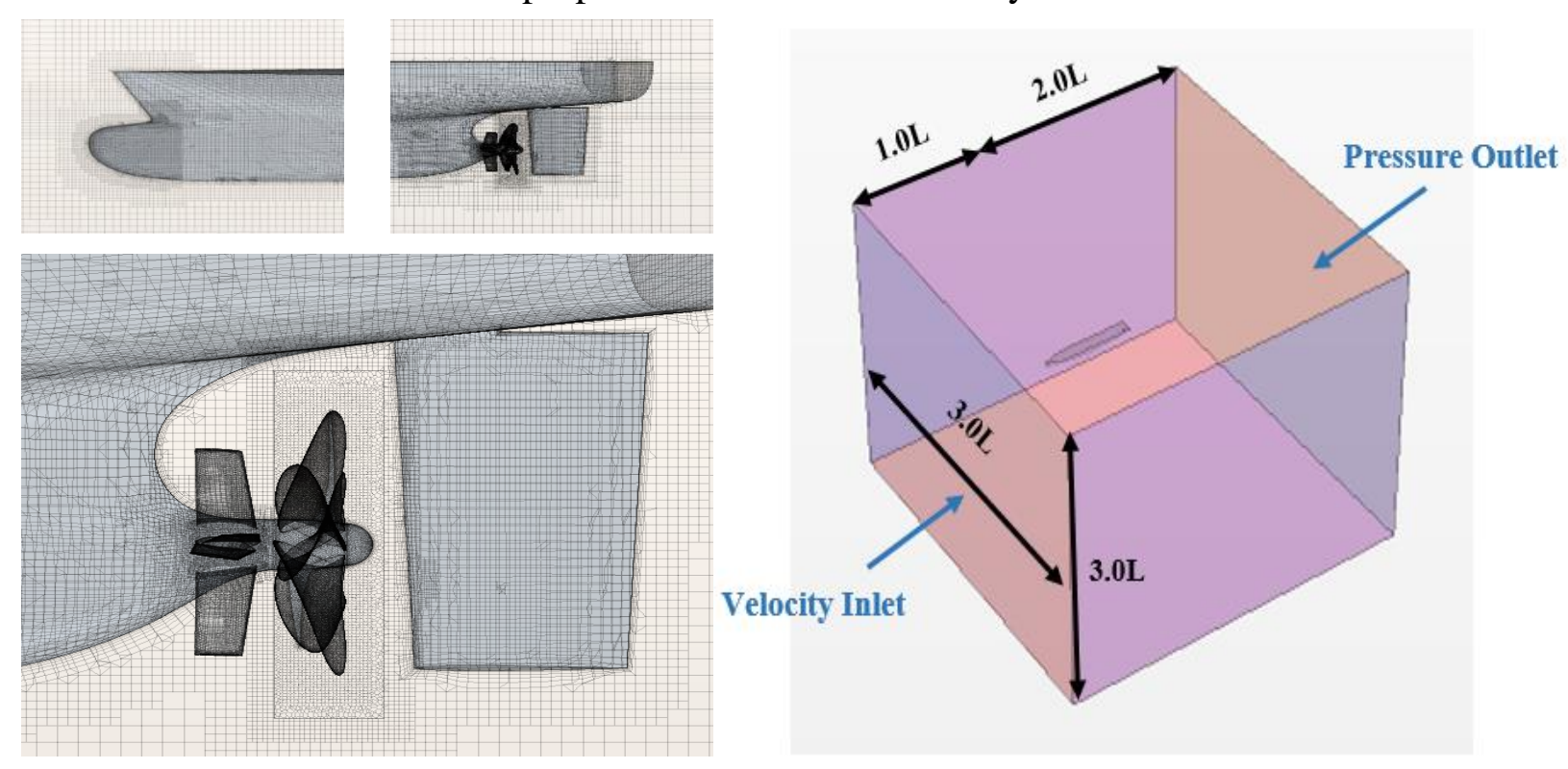

Fig. 10 Grid systems and boundary conditions of CFD for the KCS with the stator

The CFD analysis results of the previous and present studies are listed in Table 8, respectively. Regarding the efficiency gain, the difference between the two results is insignificant: $3.97 \%$ for the previous results and $3.94 \%$ for the present computation. Furthermore, the insignificant difference in each component of torque and the speed of revolution is listed in the table, which are reasonable considering the difference in blade thickness and the grid system for each computation. 
Table 8 Computational results of the self-propulsion (model scale)

\begin{tabular}{|c|c|c|c|}
\hline & $\mathrm{n}_{\mathrm{M}}(\mathrm{rps})$ & $\mathrm{Q}_{\mathrm{M}}(\mathrm{N} \cdot \mathrm{m})$ & $2 \pi \mathrm{n}_{\mathrm{M}} \mathrm{Q}_{\mathrm{M}}(\mathrm{W})$ \\
\hline Previous W/O Stator & 11.22 & 1.1540 & 81.35 \\
\hline Previous W/ Stator & 11.07 & 1.1230 & 78.12 \\
\hline Difference (\%) & -1.34 & -2.69 & -3.97 \\
\hline Present W/O Stator & 11.05 & 1.2689 & 88.09 \\
\hline Present W/ Stator & 10.59 & 1.2718 & 84.62 \\
\hline Difference (\%) & -4.16 & 0.28 & -3.94 \\
\hline
\end{tabular}

\section{Fluid-Structure Interaction Analysis of PSS for KCS}

Although flexible materials have been previously applied to propellers, there are limited studies on the ESD with flexible materials. In this study, a flexible composite material [20] was adopted by considering not only the convergence, but also a practical application, as listed in Table 9 whose material has been treat in the research of flexible propeller [20]. As previously indicated, the thickness of the stator blade was intentionally reduced ( $20 \%$ thinner) when compared to the previous design [6] by considering the deformation of the stator blade and the efficiency gain. There is an actually vacant volume inside of a normal steel type fullscale stator. In the present study the flexible stator is assumed to be solid and somewhat the low flexibility of material was adopted in consideration of structural point of view for the practical application. The further structural study is expected to be conducted in the near future.

Table 9 Material properties of flexible stator

\begin{tabular}{|c|c|c|c|}
\hline & $\begin{array}{c}\text { Young`s Modulus } \\
(\mathrm{Gpa})\end{array}$ & Poisson Ratio & Density $\left(\mathrm{kg} / \mathrm{m}^{3}\right)$ \\
\hline Specification & 10.0 & 0.17 & 2200 \\
\hline
\end{tabular}

A numerical analysis was conducted for both flexible and rigid stators to determine the difference in the performance according to the deformation. Although the CFD validation for the present asymmetric stator system was conducted (Table 8), it may be necessary to compare these results with a rigid case using the developed FSI analysis system. The computational conditions and grid system were the same as those mentioned in Section 4. The material properties and computational conditions of the flexible stator blade are listed in Tables 9 and 10, respectively. A structural hexa-grid system was used for analysing the present system (via FSI analysis) to reduce the computation time, as depicted in Fig. 11. The CFD-FEM calculation took about 10 days by 140 cores of CPU (Intel_Xeon_E52650_v2_@_2.60GHz). It almost took about 5 times more than only CFD calculation. 
Table 10 Computational conditions of the FSI analysis for the flexible case

\begin{tabular}{|l|l|}
\hline Program & $\begin{array}{l}\text { Star-CCM+ (Ver. 11.02) } \\
\text { Abaqus (Ver. 6.14) }\end{array}$ \\
\hline Governing Equation & Incompressible RANS Equation \\
\hline Turbulence Model & Realizable к- $\varepsilon$ model \\
\hline Coupling Scheme & Implicit \\
\hline Rotation Method & Sliding Mesh \\
\hline Time Step & 0.002s \\
\hline Physical Time & 20s \\
\hline Grid No. & $\begin{array}{l}\text { Approximately 3,500,000 } \\
\text { (Fluid region: 2.6M, Rotating region: } \\
\text { 0.9M, Stator surface: 27,000) }\end{array}$ \\
\hline
\end{tabular}

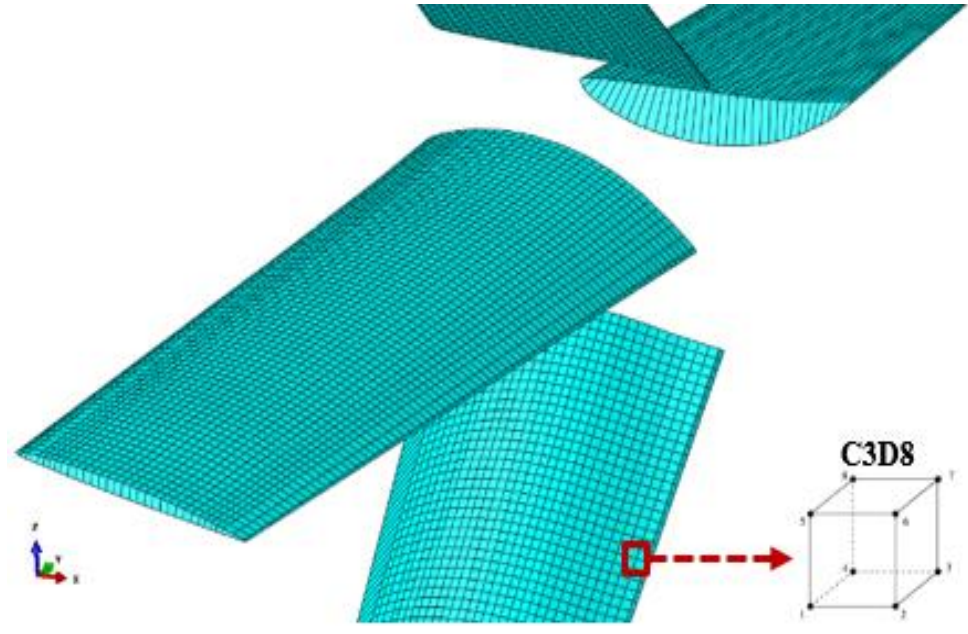

Fig. 11 Structured grid for the Abaqus solver

Regarding the rigid case, the computed results listed in Table 11 are significantly similar to the previous CFD results listed in Table 6 using the FSI analysis system without deformation. The slight difference that can be observed may have occurred due to the numerical error caused by the use of a different analysis system. Regarding the flexible case, the deformation at the tip of the flexible asymmetric pre-swirl stator finally converged to approximately $0.3 \mathrm{~mm}$, as depicted in Fig. 12. The self-propulsion performances of the flexible and rigid cases were compared, as listed in Table 11. Considering efficiency, the delivered power of the flexible case is approximately $0.5 \%$ less than that of the rigid asymmetric pre-swirl stator. Although the deformation is small the flow around stator especially around $0.7 \mathrm{R}$ is favorable compared to the rigid case while the difference is not clearly seen at tip as shown in Fig. 13. Fig. 14 shows the flow speed distribution from the leading edge view that indicates the reason of the difference between the flexible and rigid blade at $0.7 \mathrm{R}$. The velocity distribution of flow in the flexible model can be seen even spanwisely compared to the rigid model as shown in Fig. 14 that is due to a deformation along the radius in flexible case although the amount is small. As the velocity difference between the pressure and suction side means the vortex at each radii the more uniformly distributed load of stator seems works better for recovering the rotational flow on the whole than the rigid case. If a more flexible material is used or the flexible material is applied to a full body ship of a more non-uniform wake such as tankers and bulk carriers of slow speed ships, the effect of this adaptation would be larger. Surface pressure distributions on the stator suction side 
were also compared, but there was little significant difference between the two models. It is shown in Fig. 15.

From the structural point of view, the stress distributions of both cases were compared as shown in Fig. 16. Although the deformation is small the difference of stress between them is larger and the maximum stress in the z-direction (opposite to gravity) where the displacement occurs is $1.745 \mathrm{e}+06 \mathrm{~N} / \mathrm{m}^{2}$ for the rigid model while flexible case is $1.377 \mathrm{e}+06$ $\mathrm{N} / \mathrm{m}^{2}$. Assuming that the external forces acting on the two models are same, it can be seen that the maximum stress generated is small for the flexible material because it resists deformation less. Fig. 17 shows the time history of maximum stress at the root part of the $2^{\text {nd }}$ blade. As the resistance against deformation decreases in the flexible case compared to the rigid case final stress of the flexible case is less than the rigid case. In addition, the fluctuating stress due to the propeller is less in the flexible case. This result seems better in structural point of view with a flexible material.

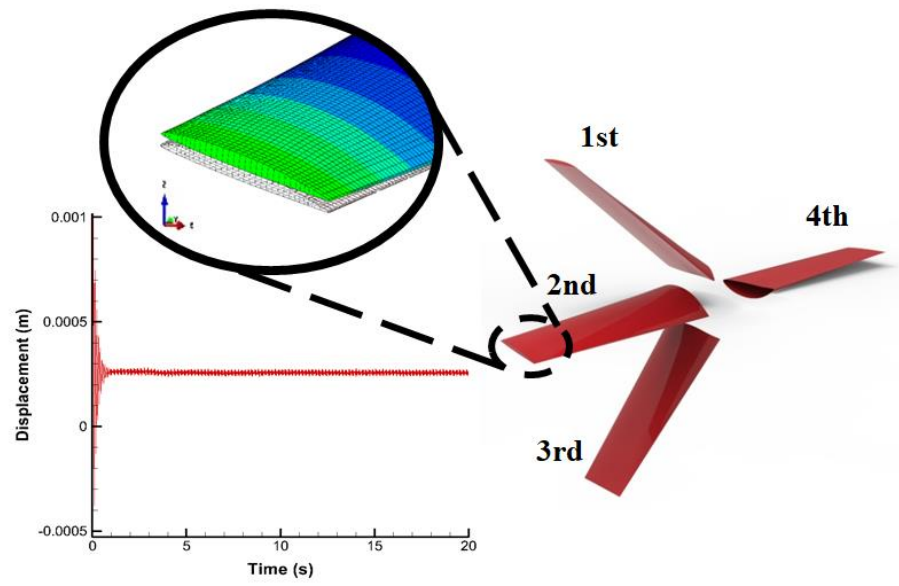

Fig. 12 Deformation in Z-direction at the node point of the tip section of the second blade

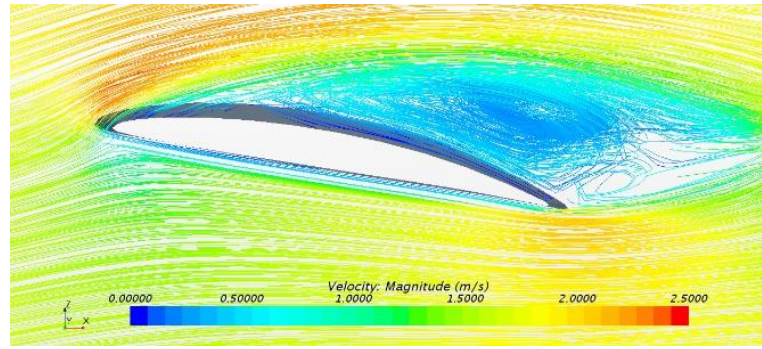

(a)

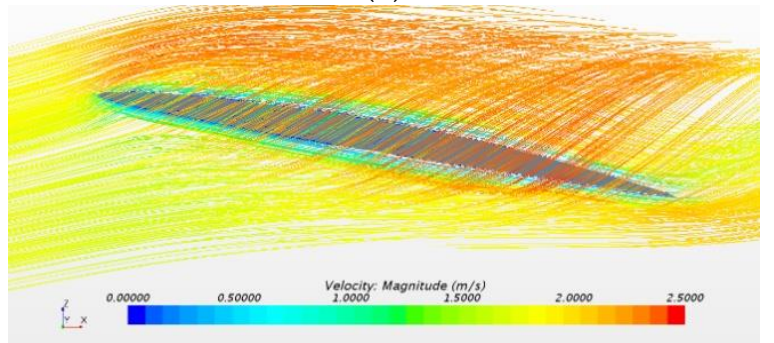

(c)

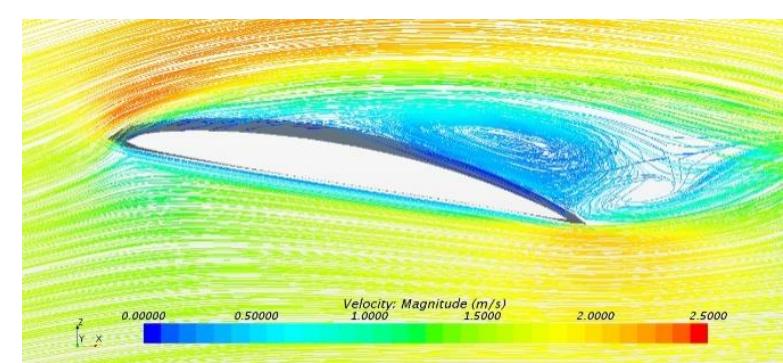

(b)

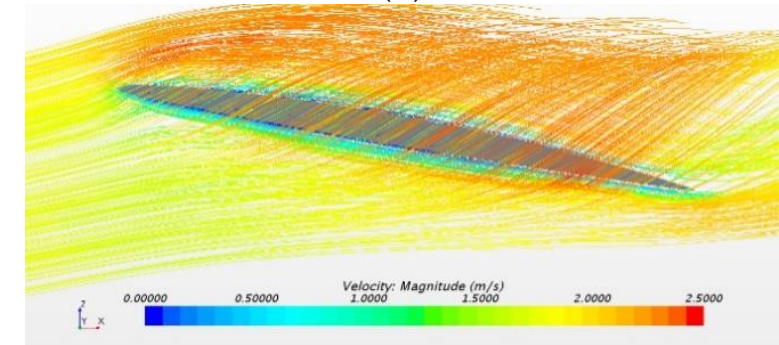

(d)

Fig. 13 Comparison of streamlines at $0.7 \mathrm{R}$ and tip section between the flexible and the rigid stators: (a) $0.7 \mathrm{R}$ streamline for rigid model (b) $0.7 \mathrm{R}$ streamline for flexible model (c) Tip streamline for rigid model (d) Tip streamline for flexible model 
Jin Gu Kang, Moon Chan Kim,

I Rok Shin, Woo Seok Jin

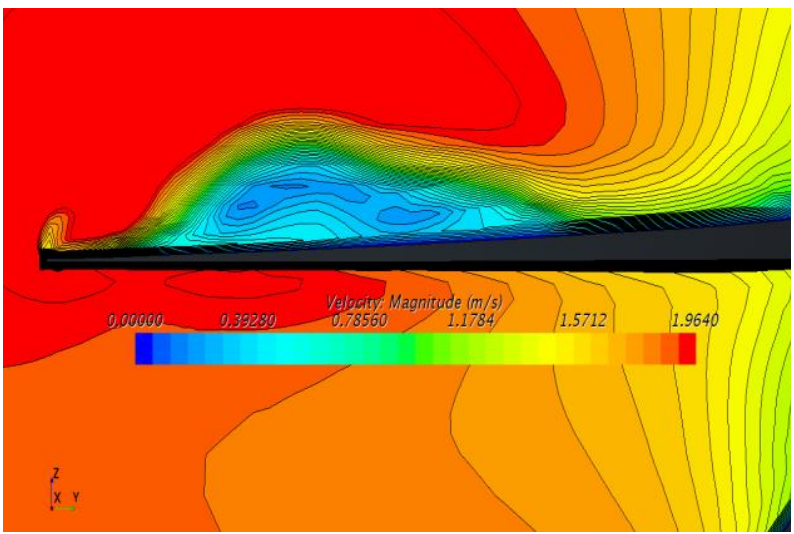

(a)
Application of a Flexible Material to an Asymmetric Pre-swirl Stator for the KRISO Container Ship

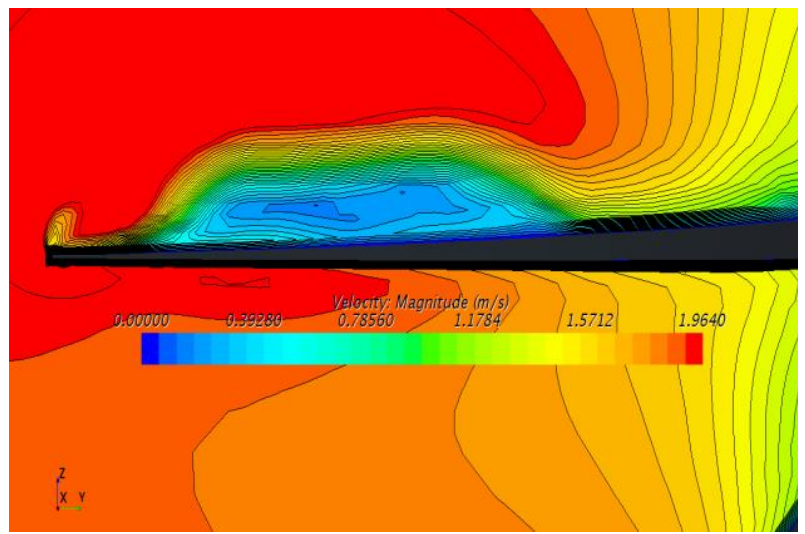

(b)

Fig. 14 Comparison of velocity distribution around 2nd blade between the flexible and the rigid stators (looking down stream, finally converged values, relative position of the stator and propeller is same): (a) Rigid model (b) Flexible model

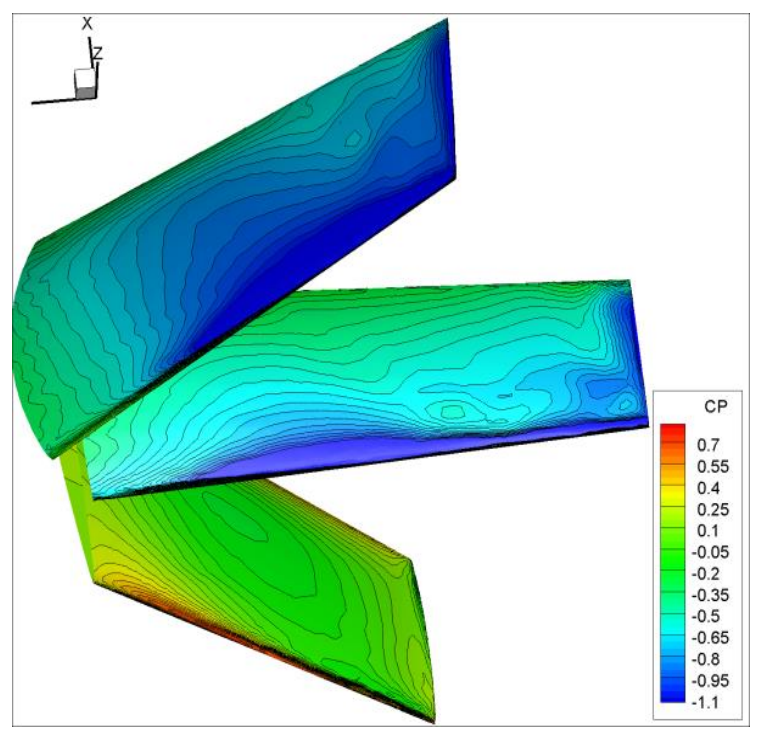

(a)

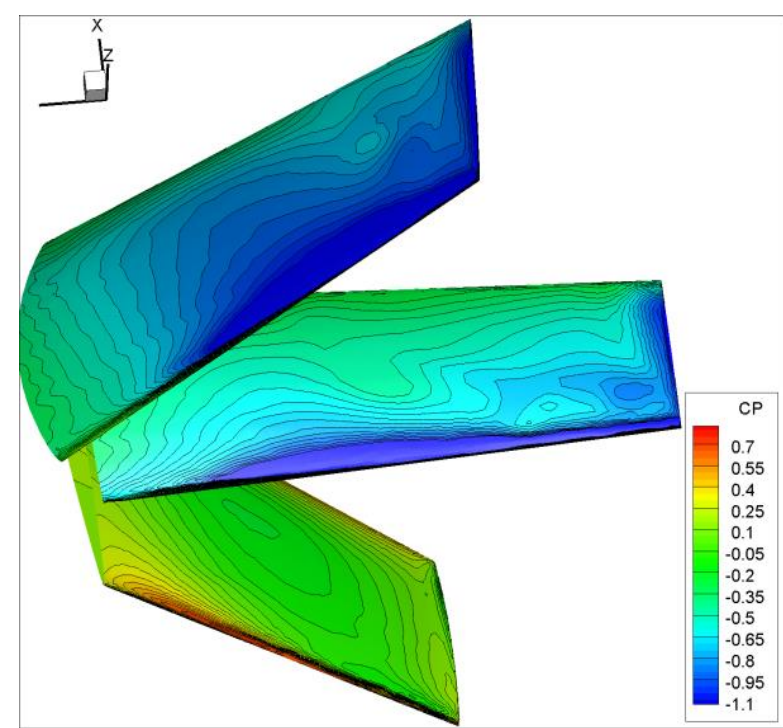

(b)

Fig. 15 Pressure distribution of stator at suction side for port side: (a) Rigid model (b) Flexible model

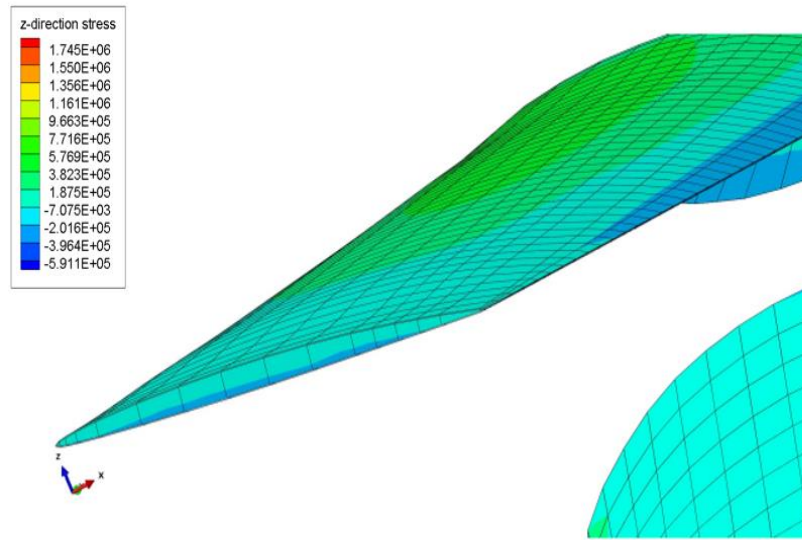

(a)

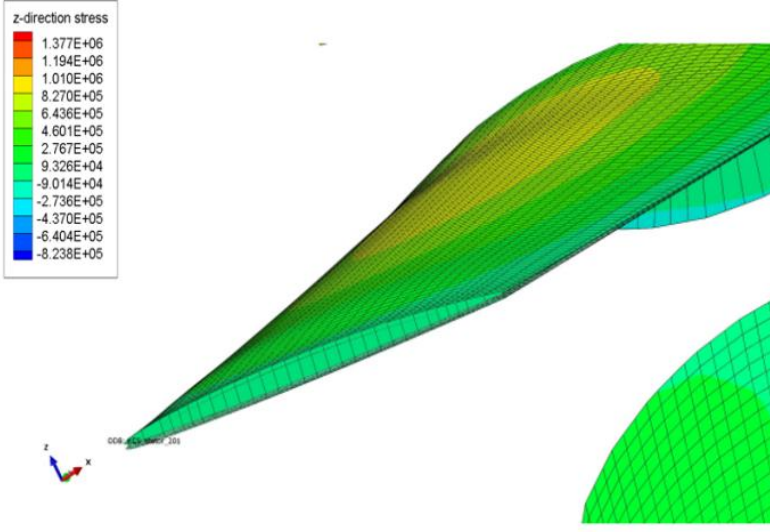

(b)

Fig. 16 Stress distribution of pre-swirl stator: (a) rigid case and (b) flexible case 


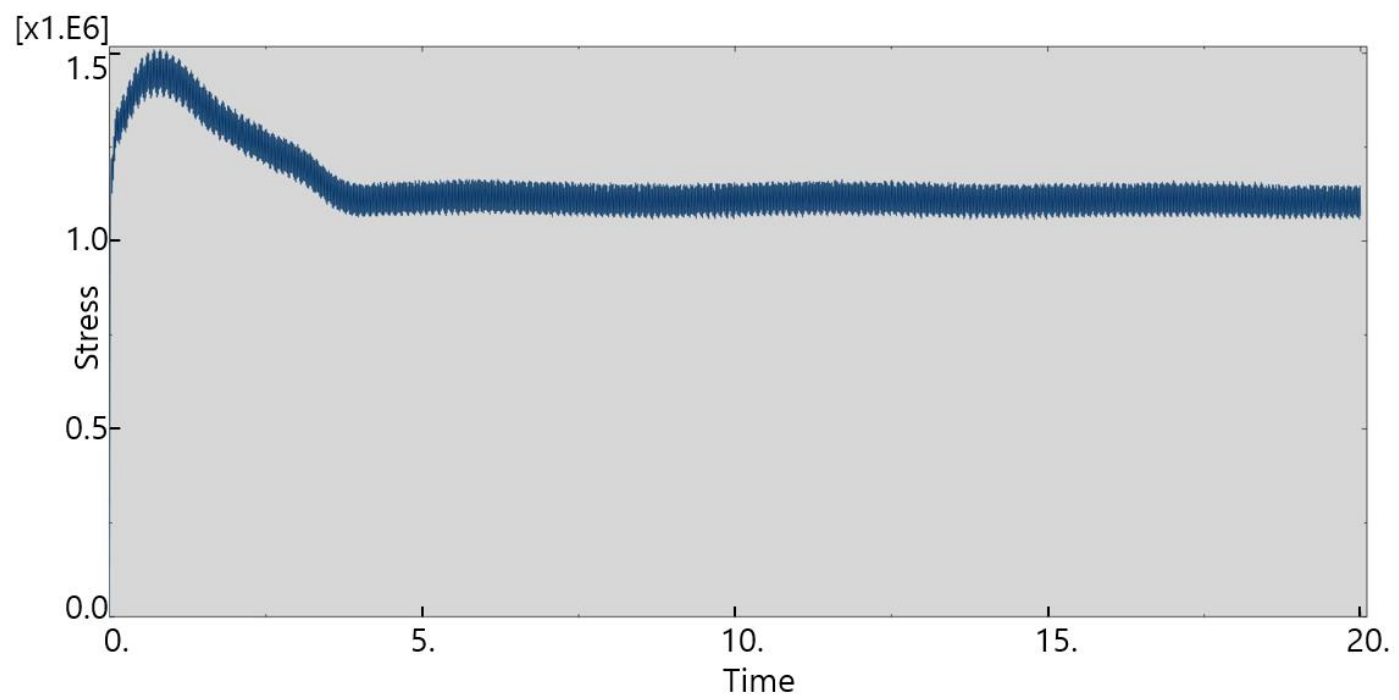

(a)

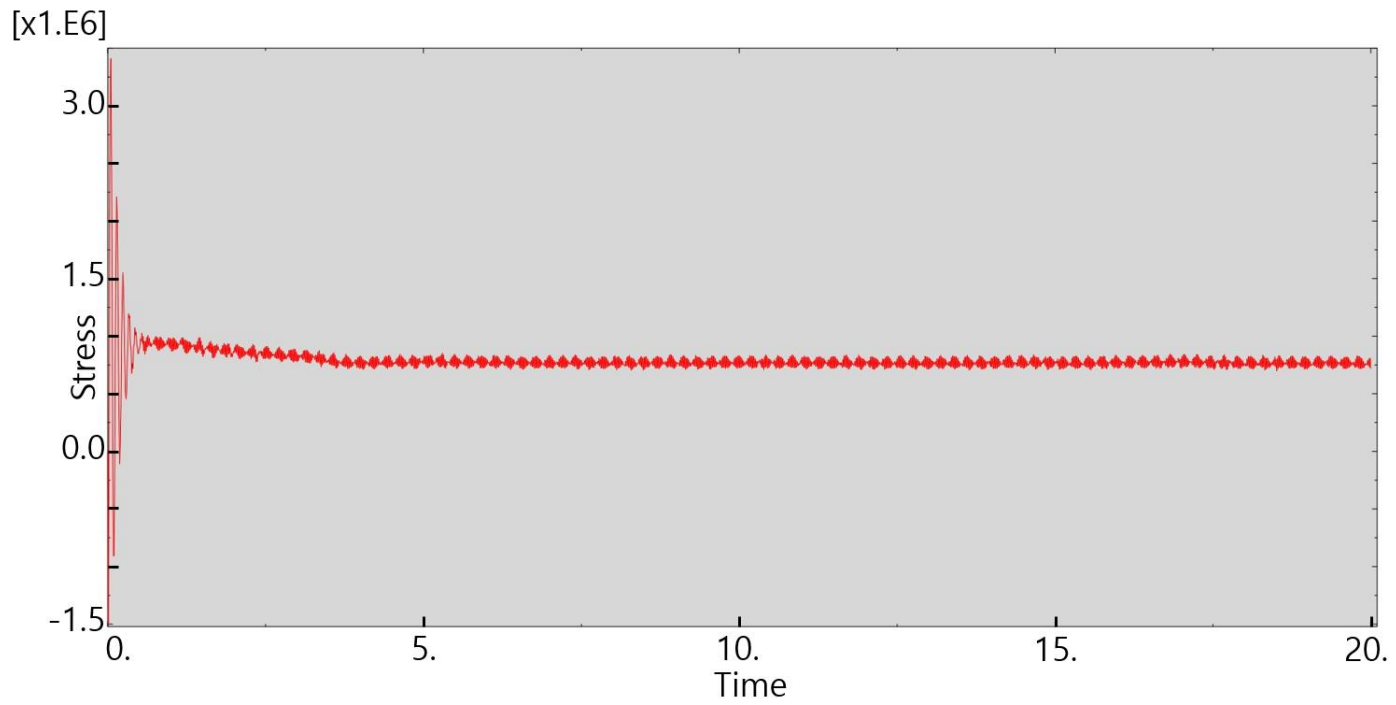

(b)

Fig. 17 Time history of maximum stress (the root part of $2^{\text {nd }}$ blade): (a) rigid case and (b) flexible case

Table 11 FSI computational results of self-propulsion

\begin{tabular}{|l|r|r|r|r|r|}
\hline & W/O Stator & \multicolumn{1}{|l|}{$\begin{array}{c}\text { W/ Stator } \\
\text { (rigid) }\end{array}$} & \multicolumn{1}{c|}{$\begin{array}{c}\text { Difference } \\
(\%)\end{array}$} & $\begin{array}{r}\text { W/ Stator } \\
\text { (flexible) }\end{array}$ & $\begin{array}{c}\text { Difference } \\
(\%)\end{array}$ \\
\hline $\mathrm{n}_{\mathrm{M}}(\mathrm{rps})$ & 11.05 & 10.56 & -4.43 & 10.56 & -4.43 \\
\hline $\mathrm{Q} \mathrm{M}(\mathrm{N} \cdot \mathrm{m})$ & 1.269 & 1.270 & 0.06 & 1.264 & -0.41 \\
\hline $2 \pi \mathrm{n}_{\mathrm{M}} \mathrm{Q}_{\mathrm{M}}(\mathrm{W})$ & 88.09 & 84.27 & -4.34 & 83.85 & -4.80 \\
\hline
\end{tabular}




\section{Discussions and Conclusions}

In this study, the propulsion performance due to deformation in flexible asymmetric pre-swirl stator for the KCS was verified via CFD-FEM-based FSI analysis. The performance of an asymmetric pre-swirl stator optimally designed for a KCS in a previous study was validated through CFD analysis, and an FSI analysis was performed for a flexible asymmetric pre-swirl stator for the KCS based on the optimally designed dimensions. A two-way implicit coupling system combined with the Star-CCM+ (fluid) and the Abaqus (structure) was established for analysing the flexible asymmetric pre-swirl stator performance. The fluidstructure interaction was validated using the flexible vertical plate problem. The validated FSI analysis was applied to a flexible pre-swirl stator. The flexible pre-swirl stator exhibited a slightly higher propulsion efficiency of $0.5 \%$ compared to the rigid case based on the power delivered by the model. If a more flexible material is used, the amount of efficiency gain would be higher; optimum flexible material is expected to be investigated after researching about the structural problem in the future. The results of this study were investigated through the streamlines near flexible stator blades and velocity distribution around stator along radius. The twisting of a flexible blade due to flow makes the flow condition more favorable, which slightly delays the flow separation and results in a favorable flow to the propeller. The velocity distribution of flow in the flexible model can be seen even spanwisely compared to the rigid model that is due to a deformation along the radius in flexible case although the amount is small. As the velocity difference between the pressure and suction side means the vortex at each radii the more uniformly distributed load of stator seems works better for recovering the rotational flow on the whole than the rigid case.

Although the flexibility of the present study is low, this study demonstrates the possibility of applying flexible materials to the ESD. If a more flexible material is used and the design parameters are optimized, the performance might be improved using a flexible stator. This flexible blade may be more applicable to a slow speed full body ship because the inflow direction to a blade is variable along the radii owing to the non-wake field. The experimental work for the present ESD is also expected to be conducted in the future because the scaling of material in model test would be another important and difficult issue.

\section{ACKNOWLEDGEMENTS}

This research was supported by Basic Science Research Program through the National Research Foundation of Korea (NRF) funded by the Ministry of Science, ICT \& Future Planning (NRF-2019R1F1A105808013).

\section{REFERENCES}

[1] Bazari, Z., and Longva, T., 2011, “Assessment of IMO-mandated energy efficiency measures for international shipping”, Lloyd`s Register, London, UK.

[2] Carlton, J. "Marine propellers and propulsion", Third edition, Butterworth-Heinemann, Great Britain, 1994.

[3] Kim, M. C., Chun, H. H., Kang, Y. D., 2004, "Design and experimental study on a new concept of preswirl stator as an efficient energy-saving device for slow speed full body ship", J. Soc. Nav. Archit. Mar.

Eng. 112, pp. 111-121.

[4] Takekuma, K., Tsuda, S., Kawamura, A., Kawaguchi, N., 1981, "Development of reaction fin as a device for improvement of propulsive performance of high block coefficient ships", J. Soc. Nav. Archit. Japan, 150, pp. 74-84. https://doi.org/10.2534/jjasnaoe1968.1981.150_74

[5] Lee, K.S., Kim, M.C., Shin, Y.J., Kang, J.G., 2019, "Design of asymmetric pre-swirl stator for KVLCC2 considering angle of attack in non-uniform flow fields of the stern”, J. Soc. Nav. Archit. Korea, 56, pp. 352-360. https://doi.org/10.3744/SNAK.2019.56.4.352 
[6] Shin, Y.J., Kim, M.C., Kang, J.G., Kim, H.U., Shin, I.R., 2019, "Validation of optimally designed statorpropeller system by EFD and CFD”, Brodogradnja: Teorija i praksa brodogradnje i pomorske tehnike, 70(3), pp. 133-151. https://doi.org/10.21278/brod70308

[7] Kim, K.S., Park, S.J., 2011, “Technique status of carbon fibers-reinforced composites for aircrafts”, $J$. Elastomers Composit., 30(6), pp. 431-439.

[8] Chase, N., Carrica, P.M., 2013, "Submarine propeller computations and application to self-propulsion of DARPA Suboff”, Ocean Engineering, 60(1), pp. 68-80. https://doi.org/10.1016/j.oceaneng.2012.12.029

[9] S., Sezen, A., Dogrul, C., Delen, S., Bal., 2018, "Investigation of self-propulsion of DARPA Suboff by RANS method”, Ocean Eng., 150(15), pp. 258-271. https://doi.org/10.1016/j.oceaneng.2017.12.051

[10] Zondervan, G.J., Grasso, N., Lafeber, W., 2017, "Hydrodynamic design and model testing techniques for composite ship propellers", Fifth International Symposium on Marine Propulsors, Espoo, Finland.

[11] Park, C.H., Jang, H.Y., Park, M.S., Im, N.K., 2013, "Result analysis of sea trial test for offshore fishing boat attached FRP rudder", J. Ocean Eng. Technol., 27(6), pp. 112-118. https://doi.org/10.5574/KSOE.2013.27.6.112

[12] Lin, H.J., Lin, J J., 1996, "Nonlinear hydroelastic behavior of propellers using a finite-element method and lifting surface theory", J. Mar. Sci. Technol., 1(2), pp. 114-124. https://doi.org/10.1007/BF02391167

[13] Young, Y.L. 2008, "Fluid-structure interaction analysis of flexible composite marine propellers", $J$. Fluids Struct., 24(6), pp. 799-818. https://doi.org/10.1016/j.jfluidstructs.2007.12.010

[14] Lee, H., Song, M.C., Suh, J.C., Cha, M.C., Chang, B.J., 2015, “A numerical study on the hydro-elastic behavior of composite marine propeller”, Fourth International Symposium on Marine Propulsors, Austin, Texas, USA.

[15] Lee, H., Hur, J., Park, J.H., Hah, Z.H., Song, M.C., Chang, B.J., 2017, “A design concept of composite marine propeller for long stroke slow speed", Fifth International Symposium on Marine Propulsors, Espoo, Finland.

[16] Hong, Y., Wilson, P.A., He, X.D., Wang, R.G., 2017, "Numerical analysis and performance comparison of the same series of composite propellers”, Ocean Eng., 144, pp. 211-223. https://doi.org/10.1016/j.oceaneng.2017.08.036

[17] Maljaars, P.J., Kaminski, M.L., 2015, "Hydro-elastic analysis of flexible propellers: an overview", Fourth International Symposium on Marine Propulsors, Austin, Texas, USA.

[18] Alfred B., 2015, "Efficient and robust partitioned solution schemes for fluid-structure interactions" Doctor dissertation, Faculty of Engineering and the Built Environment, University of Cape Town, Republic of South Africa.

[19] Luhar, M., Nepf, H.M., 2011, "Flow-induced reconfiguration of buoyant and flexible aquatic vegetation", Limnol. Oceanog., 56(6), pp. 2003-2017. https://doi.org/10.4319/1o.2011.56.6.2003

[20] Jang, H.G., Nho, I.S., Hong, C.H., Lee, C.S., 2012, "Design algorithm of flexible propeller by fluidstructure interactive analysis", J. Soc. Nav. Archit. Korea, 49(6), pp. 528-533. https://doi.org/10.3744/SNAK.2012.49.6.528

Submitted: 29.09.2021. Jin Gu Kang, wind0980@naver.com

Moon Chan Kim*, kmcprop@ pusan.ac.kr

Accepted: $\quad$ 04.12.2021. I Rok Shin,

Woo Seok Jin

Department of Naval Architecture and Ocean Engineering, Pusan National University, South Korea 